\title{
Comparison of numerical and experimental results of water-pipe wall interaction
}

\author{
Ali Heidari ${ }^{1}$, Poria Ghassemi $^{2}$ \\ ${ }^{1}$ PhD, Civil Engineering, Shahrekord University, Iran \\ ${ }^{2}$ MSc, Civil Engineering, Shahrekord University, Iran \\ *Corresponding author E-mail: poria.gh_fxprice@yahoo.com
}

Copyright $\odot 2015$ Ali Heidari, Poria Ghassemi. This is an open access article distributed under the Creative Commons Attribution License, which permits unrestricted use, distribution, and reproduction in any medium, provided the original work is properly cited.

\begin{abstract}
Tube wall analysis on unsteady network flow of pipe shows that the column is separated when it reached to vapor pressure. In this study, we experiment dynamic behavior of a fluid distribution pipe system. The model used in is a straight suspended pipe, which is striked by a solid steel bar. Then the results of pressure change in different parts of pipe had been studied and compared with valid results.
\end{abstract}

Keywords: Fluid and Structure Interaction; Unsteady Current; Pressure Variation Curve.

\section{Introduction}

The non-permanent currents are the one that its characteristics in each place are changed by period of time. When currents change from permanent to non-permanent condition, the non-permanent current among is called damping (transient). Water hammer is a kind of damping current which it could be created by closing faucet or suddenly pump stopping in pipe line.

Pressure change in a pipeline system causes dynamic displacements of the pipe structure that are longitudinal and lateral. These structural seismic could cause significant forces in mainstays. Furthermore, it affects the pressure waves of inside duct with affecting the continuity equation and the boundary condition. Thus, there is an interaction between fluid and pipeline structure and both have mutual influence. So for system analyzing, the equation of fluid movement and dynamic movement of structure should be written simultaneously and solve with the appropriate method.

Fluid interferes - structure in the network pipe was first proposed in 1956 by Askalat [3]. He presented to interfere equation of water hammer. After that this issue is continuously studied and different methods (coupled, semi-coupled) and algorithm is proposed for numeral modeling which the most important ones could be solving interfere equation of a pipe vibration in characteristic bank lines method by Wiggert [5] and after that Tijsseling [4], structural equation with finite element and hydraulic equation by characteristic bank lines method [6] and analytical solving of fluid-structure interfere [3].

Tijsseling and Vardy [2] had an experiment on a T pipe system in order to study ESI impacts and separation of liquid column. This experiment could be done by adjusting the static pressure inside pipe system in a resident fluid state. This experiment has been done frequently for confirming correctness and the results are the same each time. Whole pipe network and striker pipe was kept suspended by some inhibitor, and some strain gauges used for recording results in different spots of the system.

One of the most important studies in this matter is Tijsseling's study [1] in which four differential equation of EFI in a straight pipe (two hydraulic flow and one axial vibration equation of second degree which is converted to two differential equation of one degree) is solved analytically. The element should be considered miniature in order to decreasing error which increases the solving time. In summary, above solutions include of a method for creating four differential equations are depended from each which in a virtual system other and then solving them by characteristics line method. 


\section{Fluid-structure interfere analysis and fluid separation phenomena}

During water hammer phenomena significant dynamic forces applied to the pipe structure. If these forces cause in the network of pipes moves, the phenomena called fluid-structure interfere occurs. It would be impossible to evaluate the behavior of the pipe or water alone and will have to be examined concurrently. Obviously it is necessary to study interactive behavior when our purpose is determining loads on structures in state of existence of motors and other components used in the network, or to determine the ultimate load of a pipe.

Cavitation occurs when the reducing pressure inside the vapor pressure of the liquid causes evaporation of the fluid. In this condition single-phase current flow converted to two-phase flow. This phenomenon is called separation of fluid column. In this case the classic equation of water hammer is not valid anymore. The objective of modeling these phenomena is to predict created pressure and their effects on structures and the abutments.

The water hammer relations are valid until the pressure inside the pipe is greater than the vapor pressure of the fluids. If the pressure is less than the vapor pressure of the fluid, fluid is removed from the liquid phase and due to its location. There is a possibility to create a vapor cavity or a vast steam region. On further investigation, Parameter void ratio is created in vapor volume ration and defined compared to vapor and liquid mixture. In the first case cavity locally and at a point (or points that are adjacent to the valve and the maximum height) is formed and its void ratio will be limited. But in the second case, a large steam region will be created as a mixture of liquid and its vapor is created as two-phase flow in a single component which its void ratio is almost zero.

There is an important assumption in the model of separation column which suggested pressure never be lesser than vapor pressure of fluid and in next steps its value is equal to vapor pressure of fluid in calculation [7], [8].

For mathematical modeling of this phenomenon, there are three well-known models, which are Discrete Vapor Cavity Model, Discrete Gas Cavity Model and Generalized Interface Vapor Cavitation Model. We use the first one because of its simplicity and high speed calculation [8], [9].

The highest and most extensive model steam discrete model that has been used for separation column modeling and Extensive cavitation are Cavitation model. One of the main advantages of this algorithm is its simple implementation. Furthermore, this model in applicable to many of the physical separation column's in the pipeline. Here the cavities are changed by calculated pressure loss. In this model, there are no significant differences between the local steam holes and a massive steam cavitation and creating and development of steam cavities to calculation spots are limited. It also assumes that pure computational (no bubbles) are exist between the two fluid points. According to this, the wave velocity is assumed constant [7], [8]. In the phase that the cavities are formed.

Calculation spots act constant like internal boundary conditions so that the pressure of these spots is equal to vapor pressure. In following, we discussed modeling methods.

\section{Strike test in the Dundee hydraulic laboratory}

The predictable results of fluid and structure could be barely obtained by implementation of tank-pipe - valve model in laboratory samples since in addition to FSI, Other factors such as vibration fulcrums, non-permanent fluid friction with the walls of the pipes, impact of valves function and other hydraulic parameters affected the experiment unintentionally. For this purpose, strike test of the fluid in the pipe where there has none of the above factors is done in order to confirm mathematical modeling of FSI in the pipe.

The first experimental model of a strike to pipe containing pressured fluid has been done in 1966 by Vardy and Fan [4] in which fluid pipe landed on a steel plate vertically. However, later due to some weakness in the experiment, it was developed in a laboratory. This system that has been shown in figure 1 consists of one pipe with length of $4.5 \mathrm{~m}$, internal diameter of $52 \mathrm{~mm}$ and wall thickness of $3.9 \mathrm{~mm}$. The pipe is closed end from both side and has been filled by pressurized fluid and suspended from ceiling by a $3.3 \mathrm{~m}$ cable so that the pipe could vibrate and moves horizontally. Non-permanent and fluid structure interactions are created by horizontal strike of a horizontal bar to end of pipe. The length of this bar is $5 \mathrm{~m}$ and is suspended by two cables. This experiment is simpler than the common tank-valve-pipe model since the pressure gradient and permanent state speed doesn't exist in length of pipe, there is no pattern needed for valve closing and we could neglect the fulcrum effect. According to the to the time scale of the experiments which is in milliseconds, friction and gravity effect is negligible. So this experiment isolated the effect of fluid interfere from axis wave propagation well. Cavitation effect will be removed by creating initial high enough pressure.

The establishment tools of this pipe such as Strain gauges and in each axial direction (horizontal) and vertical setting and Manometer is done completely and differential spot. Furthermore, the moment of pipe and bar strike and the event after it are recorded by a camera. The velocity of striker is determined by this film tight before collision. The most important note about this experiment is that the length of the striker bar must long enough so that the pipe is separated due to the strike not from a bar tend to go back. The bar striker goes back when created a wave of striking goes to end of bar and comes back again. Other features of this experiment are listed in table 1. 

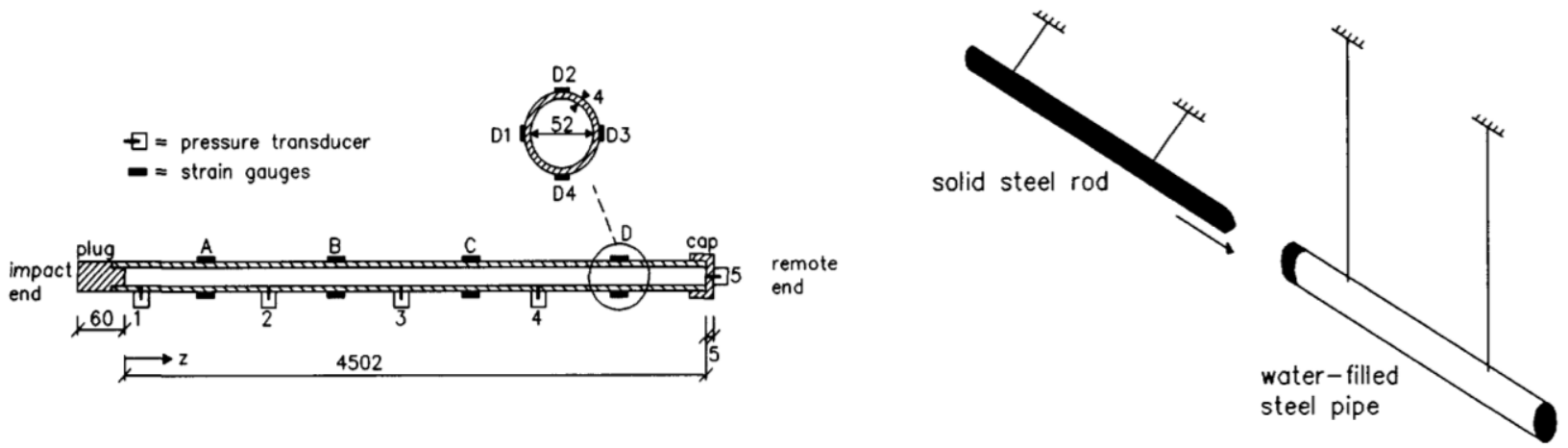

Fig. 1: Right: The Physical Model in Dundee Test [4], Left: The Placement of Instruments on Pipe

Table 1: Input Data in Dundee Test [4]

\begin{tabular}{|l|l|l|}
\hline Water-filled pipe & Position of instrumentation & Solid steel rod \\
\hline$L=4.502 \mathrm{~m}$ & $z(\mathrm{PT} 1)=0.0195 \mathrm{~m}$ & $L_{r}=5.006 \mathrm{~m}$ \\
$R=26.01 \mathrm{~mm}$ & $z(\mathrm{PT} 2)=1.1265 \mathrm{~m}$ & $R_{r}=25.37 \mathrm{~mm}$ \\
$e=3.945 \mathrm{~mm}$ & $z(\mathrm{PT} 3)=2.2510 \mathrm{~m}$ & $E_{r}=200 \mathrm{GPa}$ \\
$\gamma=0$ & $z(\mathrm{PT} 4)=3.3760 \mathrm{~m}$ & $\rho_{r}=7848 \mathrm{~kg} / \mathrm{m}^{3}$ \\
$K=2.14 \mathrm{GPa}$ & $z(\mathrm{PT} 5)=4.5020 \mathrm{~m}$ & $V_{0 r}=0.739 \mathrm{~m} / \mathrm{s}$ \\
$\rho_{f}=999 \mathrm{~kg} / \mathrm{m}^{3}$ & $z(\mathrm{SGA})=0.5740 \mathrm{~m}$ & \\
$E=168 \mathrm{GPa}$ & $z(\mathrm{SGB})=1.6880 \mathrm{~m}$ & \\
$\rho_{t}=7985 \mathrm{~kg} / \mathrm{m}^{3}$ & $z(\mathrm{SGC})=2.8140 \mathrm{~m}$ & \\
$\nu=0.29$ & $z(\mathrm{SGD})=3.9440 \mathrm{~m}$ & \\
$f=0.01$ & $z(\mathrm{LDV})=0.0465 \mathrm{~m}$ & \\
$m_{1}=1.2866 \mathrm{~kg}$ & & \\
$m_{2}=0.2925 \mathrm{~kg}$ & & \\
$H_{v}=-1000 \mathrm{~m}$ & & \\
(no cavitation) & & \\
\hline
\end{tabular}

\section{Results}

\subsection{Results of strike mode regardless of the separation of liquid column}

The results of fluid pressure indifferent spot include end of the left, right and middle is shown in figure 2. As it has been seen these results are similar to the experimental result and numeral result of Tijsseling thesis. Note that his results are about solving by fully MOC method, while these results are related with solving by MOC-FEM method. The partial different between these result is because that the FEM is weak in instant changes modeling.

\subsection{The results of strike considering the separation of liquid column}

In this section, the results of pressure change during the midpoint of the pipe are proposed in lieu of 2 initial different pressures. The experimental results are in accordance of Tijsseling's thesis results. Following diagram is proposed in initial pressure of $1.44 \mathrm{mp}$ and $0.33 \mathrm{mg}$. The results are obtained in an initial 10 second of the strike. 

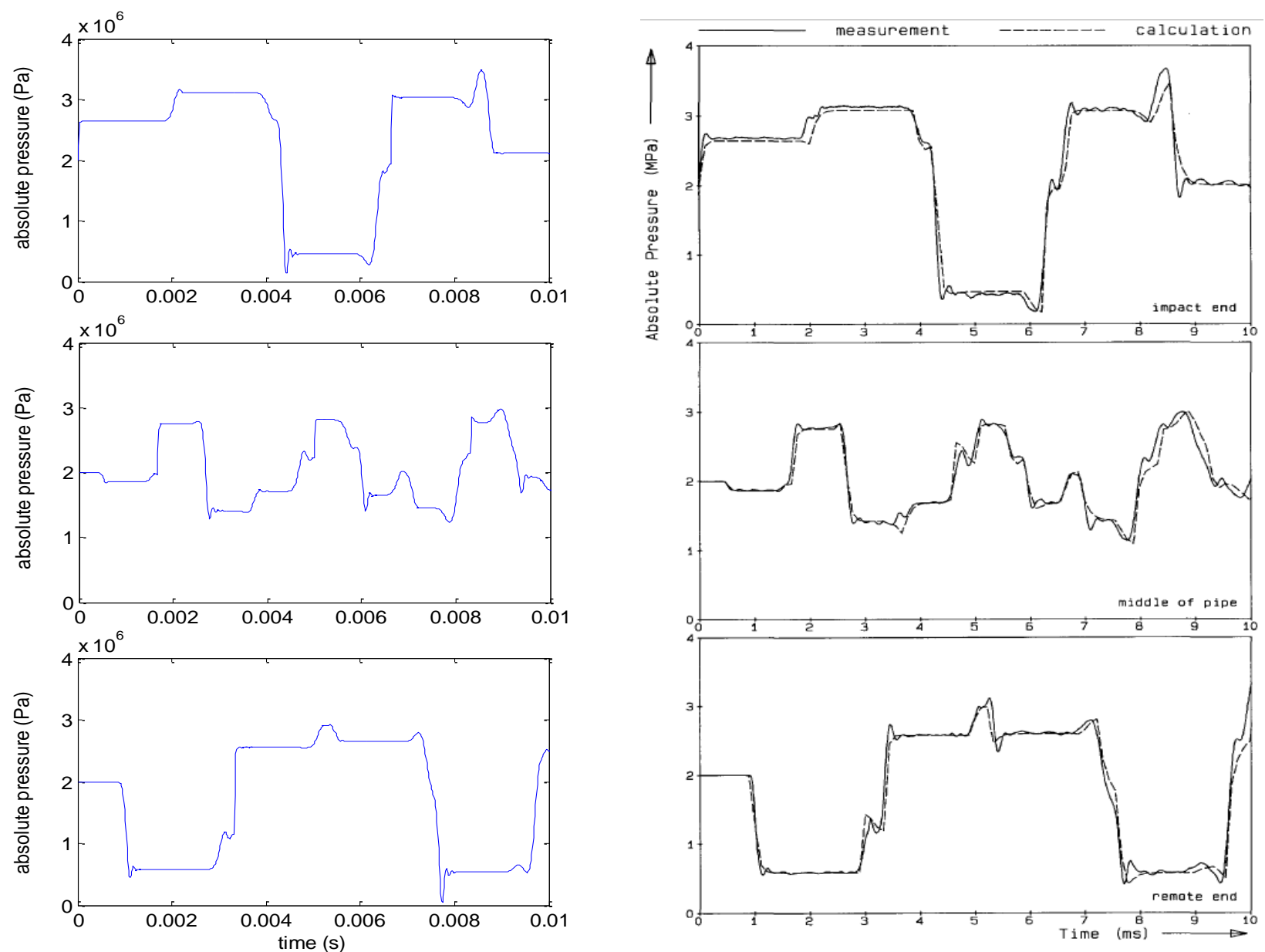

Fig. 2: The Fluid Pressure in Strike Test, Top: The Strike Point, Middle: Pipe Midpoint, Bottom: The Endpoint of Pipe

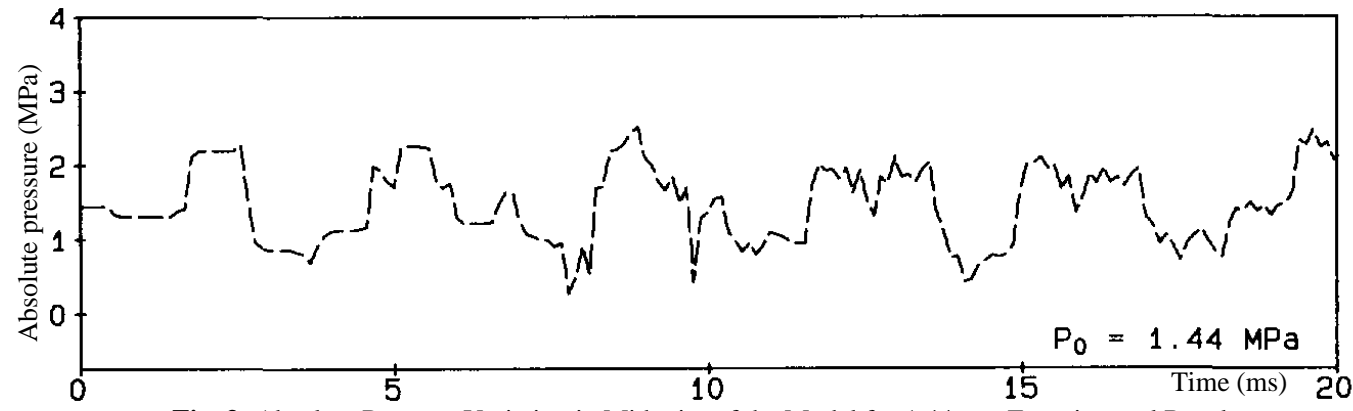

Fig. 3: Absolute Pressure Variation in Midpoint of the Model for 1.44mpa Experimental Results.

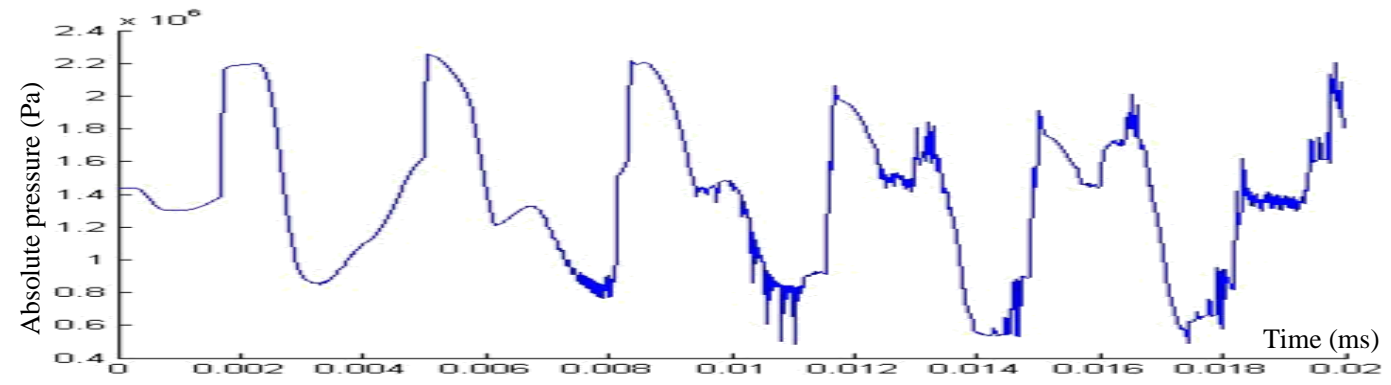

Fig. 4: Absolute Pressure Variation in a Midpoint of the Model for 1. 44 mpa Numerical Results. 


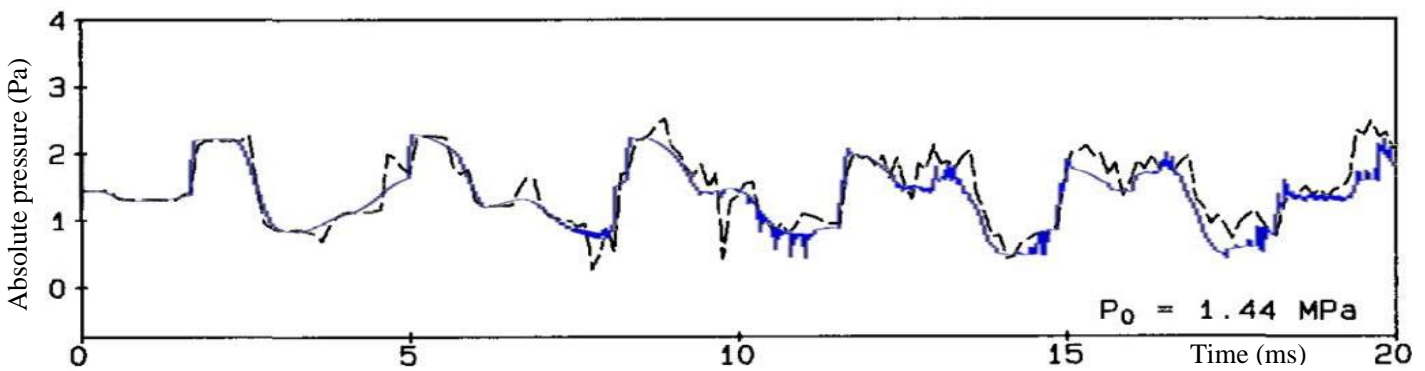

Fig. 5: Absolute Pressure Variation in Midpoint of the Model for 1.44 mpa Comparison of Experimental and Numerical Results.

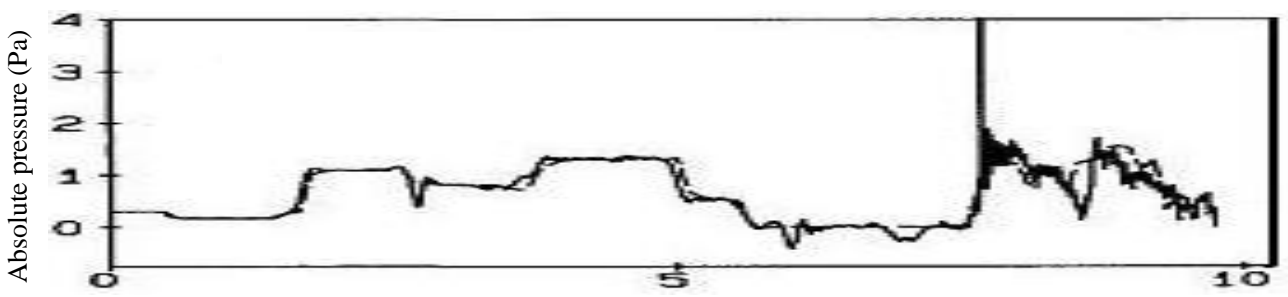

Fig. 6: Absolute Pressure Variation in Midpoint of the Model for 0.31 Mpa Experimental Results.

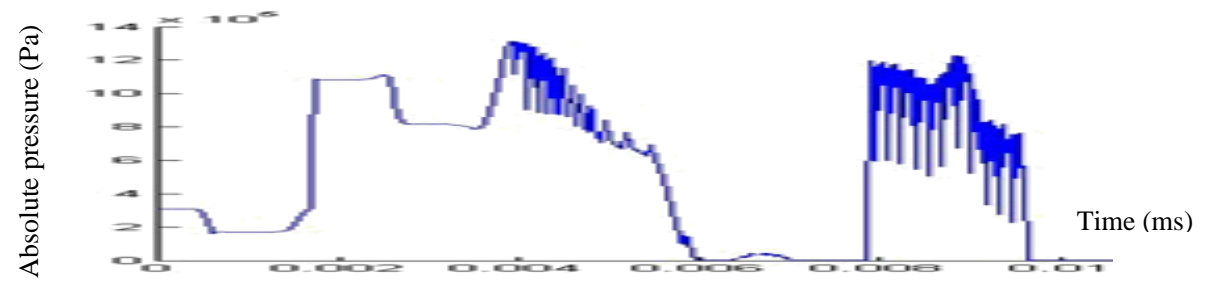

Fig. 7: Absolute Pressure Variation in Midpoint of the Model for 0.31 Mpa Numerical Results.

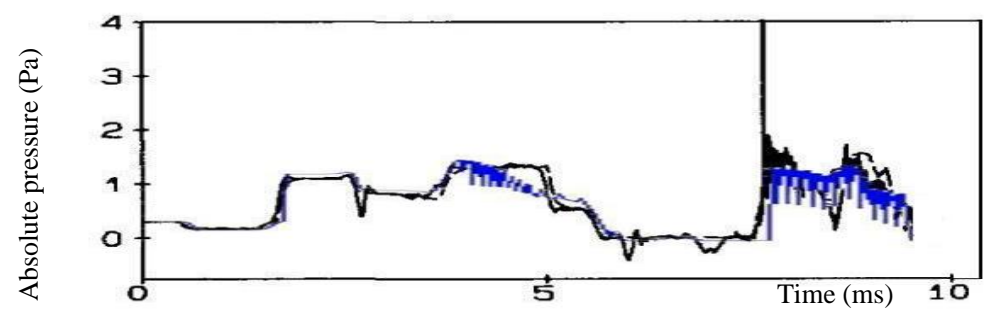

Fig. 8: Absolute Pressure Variation in Midpoint of the Model for 0.31mpa Comparison of Experimental and Numerical Results.

According to adaptive figure, which obtained with a regard to phenomenon of liquid column separation, there is a good adaption in general trend diagram so that even the terminal high volatility is the same.

\section{Conclusion}

Fluid-structure interaction (FSI) in pipe systems is being focused while the dynamic behavior of the pipe is influenced by water hammer phenomenon. The main goal of the current research thesis is to introduce a numerical model in MATLAB. It should be emphasized that column separation is also included in the solutions. The presented models are pipe systems and also suspended pipes. Then, the results from numerical and experimental observations are being compared.

Column separation phenomenon is also modeled applying the so called discrete vapor cavity model (DVCM). The mentioned model is simple and easy to be inserted in the provided program.

Finally, it should be added that FSI effects are so important and consideration of column separation is recommended seriously. The comparison of results shows suitable convergence between the numerical and experimental results.

\section{References}

[1] Tijsseling, A.S., (1996), "Fluid-structure interaction in liquid-filled pipe systems: a review", Journal of Fluids and Structures, 10, 109-146. http://dx.doi.org/10.1006/jfls.1996.0009.

[2] Tijsseling, A.S. (1993), "Fluid-structure interaction in case of water hammer with cavitation", PhD Thesis, Delft University of Technology, Delft, The Netherlands. 
[3] Wiggert, D.C., Otwell R.S., Hatfield, F.J. (1985), "The effect of elbow restraint on pressure transients", ASME Journal of Fluids Eng. 107, 402-406. Discussed by Schwirian, R.E. and Walker, J.S. in 108, 121-122.

[4] Wiggert, D.C, Tijsseling, A.S, (2001), "Fluid transients and fluid-structure interaction in flexible liquid-filled piping", ASME Applied Mechanics Reviews, 54, 455-481. http://dx.doi.org/10.1115/1.1404122.

[5] Tijsseling, A.S., (2008), 'Investigation of fluid-structure interaction with various types of junction coupling' 10th International Conference on Pressure Surges, BHR Group, Edinburgh, Scotland, UK 14-16 May, delegate bag.

[6] Bergant A., Tijsseling, A., Vítkovský, J.P., Covas, D., Simpson, A., and Lambert, M., (2008) "Parameters affecting water-hammer wave attenuation, shape and timing. Part 1: mathematical tools", IAHR Journal of Hydraulic Research, 46(3), 373-381. http://dx.doi.org/10.3826/jhr.2008.2848.

[7] Bergant A., Tijsseling, A., Vítkovský, J.P., Covas, D., Simpson, A., and Lambert, M., (2008) "Parameters affecting water-hammer wave attenuation, shape and timing. Part 2: case studies", IAHR Journal of Hydraulic Research, 46(3), 382-391. http://dx.doi.org/10.3826/jhr.2008.2847.

[8] Tijsseling, A.S., "Exact solution of linear hyperbolic four-equation system in axial liquid-pipe vibration" Journal of Fluids and Structures, Vol 18, Issue 2, September 2003, pp. 179-196. http://dx.doi.org/10.1016/j.jfluidstructs.2003.07.001.

[9] Tijsseling, A.S., Vardy, A.E., "Fluid-structure interaction and transient cavitation tests in a T-piece pipe", Journal of Fluids and structures 20 (2005), July 2005 . 